\title{
Use of profession-role exchange in an interprofessional student team-based community health service-learning experience
}

\author{
Jun Wang ${ }^{*}$ D, Jie Guo, Yubin Wang, Dan Yan, Juan Liu, Yinghong Zhang and Xianmin Hu*
}

\begin{abstract}
Background: During interprofessional clinical practice, compared to understanding of one's own professional role and function, it might be more difficult to clarify the roles and contributions of the other health-care team members because of the inter-professional barrier. In order to provide students the opportunity for real experience with other professions in team environments and enhance their perceptions of other professions' roles, this study developed a comprehensive and multi-dimension extracurricular interprofessional education (IPE) model through designing and integrating a profession-role exchange component, that was medical students as pharmacists or nurses, pharmacy students as physicians or nurses, and nursing students as physicians or pharmacists in the interprofessional health-care student team, into the service learning experience in a real community setting.

Methods: In this pre/post-intervention study, the effect of integrated profession-role exchange experiences on the students' attitudes towards interprofessional collaboration and their role clarification was evaluated among 60 student volunteers (20 medical students, 20 pharmacy students and 20 nursing students). All involved students were divided into the profession-role exchange intervention group and the control group. Subjects in the control group did not participate the profession-role exchange experiences, the other IPE procedures were the same for both groups. Three survey instruments for attitudes toward interprofessional clinical collaboration were respectively used to measure the students' attitudes toward physician-pharmacist, physician-nurse and nurse-pharmacist collaborations. "Roles and responsibilities" subscale of Readiness for Interprofessional Learning Scale was used to evaluate the overall role clarification during IPE.
\end{abstract}

Results: Compared to the control IPE activity, the addition of profession-role exchange component resulted in the significant increase in students' positive attitudes towards interprofessional collaboration, and the enhancement of students' role awareness.

Conclusions: The profession-role exchange might be more effective and better initiate students to the practice of interprofessional collaboration, and could be used as an effective IPE tool for improving the role awareness of health-care students.

Keywords: Interprofessional education, Profession-role exchange, Role-play, Community service learning, Integration

\footnotetext{
* Correspondence: wangjun@wust.edu.cn; huxianmin@wust.edu.cn

College of Medicine, Wuhan University of Science and Technology, Wuhan, China
}

(c) The Author(s). 2020 Open Access This article is licensed under a Creative Commons Attribution 4.0 International License, which permits use, sharing, adaptation, distribution and reproduction in any medium or format, as long as you give appropriate credit to the original author(s) and the source, provide a link to the Creative Commons licence, and indicate if changes were made. The images or other third party material in this article are included in the article's Creative Commons licence, unless indicated otherwise in a credit line to the material. If material is not included in the article's Creative Commons licence and your intended use is not permitted by statutory regulation or exceeds the permitted use, you will need to obtain permission directly from the copyright holder. To view a copy of this licence, visit http://creativecommons.org/licenses/by/4.0/ The Creative Commons Public Domain Dedication waiver (http://creativecommons.org/publicdomain/zero/1.0/) applies to the data made available in this article, unless otherwise stated in a credit line to the data. 


\section{Background}

Along with the rapid advancement of modern healthcare practices, an interprofessional care model has been well-accepted to be important for supporting a comprehensive patient-centred service provision through blending complementary knowledge and skills from multiple health professions, such as medicine, nursing and pharmacy [1-4]. Through working together in team to care for patients, this interprofessional care model makes possible the best use of resources, improves outcomes, and is able to meet increasingly complex health needs of patients [4]. As an essential element of interprofessional practice and collaboration, clear perceptions of interprofessional team members regarding their professional roles are crucial for the effectiveness of interprofessional care [2, 3]. To successfully participate in a wellfunctioning interprofessional team, health-care professionals first need to understand the roles of their own and other team members.

The role is considered to represent "a set of expectations in the sense that it is what one should do" [2]. The role perceptions of health-care professionals would translated into actual actions in clinical practice, thus are essential for improving patient care and achieving interprofessional team success $[2,3,5,6]$. Currently, health-care educational models in most regions of the world, for example, in China, focus on uni-professional training [7]. Therefore, health-care professionals have few opportunities to understand the professional characteristics and practices of other professionals during learning and patient care. Therefore, compared to understanding of one's own professional role and function, it might be more difficult to clarify the roles and contributions of the other health-care team members. Knowledge of professional role of others has been mentioned as a key competency that is required for successful interprofessional practice and collaboration [8]. In order to provide a comprehensive and optimal team-based health care, each team member should revolve around specific role expectations and meet perceived professional responsibilities. Team members as a group must have an understanding of the competencies and skills which each team member could contribute, and can determine who is the best suitable one to implement the given clinical intervention that is required in a given situation [2]. Nevertheless, a lack of awareness, definition and recognition of one another's role was still believed as a main conceptual barrier to interprofessional collaboration as perceived by the involved actors $[4,9,10]$, which need to be overcome in the future.

Interprofessional education (IPE), whereby students from different health-care professions learn and practise together, has shown to have a positive impact on team work in the students' future health-care practice, contribute to train effectual health-care teams and optimize future holistic patient care $[10,11]$. In order to prepare the students to interprofessional team practice, health-care education programs should provide adequate learning opportunities that enable students to interact with potential professional team members, gain insight into the roles, professional cultures, and contributions of collaborating team members $[2,11]$. Among the varied educational initiatives for teaching interdisciplinary teamwork, community service learning has attracted great interest from health-care educators [7, 12-15]. The service/learner model, a team approach to experiential education, has been suggested as a potential teaching method for IPE [16]. This model challenges the learners to effectively work together to address real clinical problems or patient education in a clinical setting, thus provides a means of linking classroom knowledge with the practical experience [17]. Community service learning is a common representation format for the service/learner model [7, 12-15]. In our previous study [7], we developed a new IPE opportunity through integrating cooperative learning into an interprofessional student team-based community service event. Cooperative learning is an instructional tool to organize students into small groups, in which students work together to help one another learn academic content [7]. In the IPE program previously conducted by our team [7], cooperative learning project was implemented before the community service event, in order to lay the foundation for good communication and shared understanding or thinking among team members. Results showed a significant increase in positive attitudes among the involved students towards interprofessional collaboration after participation in this IPE activity. The use of cooperative learning interacting with colleagues from other professions was beneficial to expand students' exposure to the role of other health-care professionals [7]. However, this previous IPE opportunity only involved medical and pharmacy students. Importantly, it is generally accepted that role clarification in interprofessional collaboration requires real experience with other professions in team environments [18]. In an effort to improve our existing IPE activity, we further speculated, if some experiential interventions were vividly integrated into the service learning experience in a real community setting, this IPE activity might be more effective and better initiate students to the practice of interprofessional collaboration.

Therefore, we proposed a conceptual framework for profession-role exchange design as a module to provide additional support for IPE. In order to explore a promising approach for enhancing students' perceptions of the role of other professions and develop a comprehensive and multi-dimension extracurricular IPE model, this study designed and integrated a profession-role 
exchange component, that was medical students as pharmacists or nurses, pharmacy students as physicians or nurses, and nursing students as physicians or pharmacists, in the interprofessional student team-based community service experience. In this protocol, the students were encouraged to experience interprofessional team working in community settings as a different role from their own professional background. Then, the effect of integrated profession-role exchange experiences on the students' attitudes towards interprofessional collaboration and their role clarification was evaluated.

\section{Methods}

\section{Study description}

A total of 60 third-year students (20 medical students, 20 pharmacy students and 20 nursing students; 19 males and 41 females) volunteered to participate in the IPE activity on May 12-13, 2018. They had learned basic disease/drug knowledge and community service skills, and were recruited via the Internet. Faculty organised an interprofessional student team-based local community diabetes self-management education. The involved students were randomly divided into the profession-role exchange intervention group and the control group. Each group was composed of 10 medical students, 10 pharmacy students and 10 nursing students. Two weeks prior to the IPE activity, all the student volunteers were informed about the aim and step of this IPE activity, organized into interprofessional teams during an initial meeting convened by faculty committee. The CONSORT guidelines were followed and the study flowchart is presented in Fig. 1.

\section{Step 1 cooperative learning}

Previously, we used cooperative learning based on sixstage model of group investigation to prepare for the subsequent community service learning [7]. The students carried out the cooperative learning in the organized interprofessional teams. Students were arranged to learn and discuss the knowledge and skills, which were required to deliver interprofessional care in the subsequent community service experience, in collaborative small-group learning situations. Moreover, students from different professions were encouraged to offer their own professional opinions about diabetes control, in order to let students from other professions understand their own professional roles and responsibilities. Meanwhile, positive collaborative relationships among the three professions could be built through the reciprocal discussion among team members. On the day before the community service IPE activity, faculty committee convened a formal meeting, in which the students were required to report on their group's cooperative learning work, present the group community diabetes self- management education project, outline and negotiate all team members' potential professional contributions.

\section{Step 2 community service learning}

Considering the prevalence of increased incidence of type 2 diabetes among the public, the hierarchical diagnosis and treatment system reforms for improving the community health service system have been initiated in response to the challenges of chronic diseases represented by diabetes in China [19]. Accordingly, Chinese health profession students have more opportunities to access to a wide variety of patients with a range of acute to chronic diabetic conditions, and learn professional diabetes-related knowledge and skills in communitybased settings. After cooperative learning, the students participated in a community service experience aiming to increase diabetes self-management education. The interprofessional student teams conducted household visits for the community residents suffering from diabetes, the list of whom was given by the community hospital, to educate them about diabetes self-management and address their health-care needs. Each interprofessional student team included 2 medical students, 2 pharmacy students and 2 nursing students. Each group (profession-role exchange intervention group or the control group) included 5 teams to visit the household. The responsibilities of health-care students from different professions were proposed and assigned based on the clinical practice and the Standards for Diabetes SelfManagement Education and Support [20](Fig. 1).

\section{Intervention profession-role exchange}

On the days the local community diabetes selfmanagement education IPE activity was conducted, in the intervention group, the profession-role exchange experiences were used to further enhance the role awareness of health-care students. As a kind of role-playing education game, profession-role exchange is an innovative simulation- based experiential learning method, in which health-care students from different professions play one another's role in an environment similar to the clinical environment. This new role experience may help students to develop awareness and valuing of the future collaborating team members' potential contributions in providing effective patient care, as well as objectively view their own role from the perspective of partners. During the community diabetes self-management education IPE activity (Step 2), students in the intervention group were required to perform the responsibilities of the students from other professions. That is, one medical student in a team should perform the responsibilities of the pharmacy students in their team; the other medical student should play the role of the partner nursing students in their team. And one pharmacy student in this 


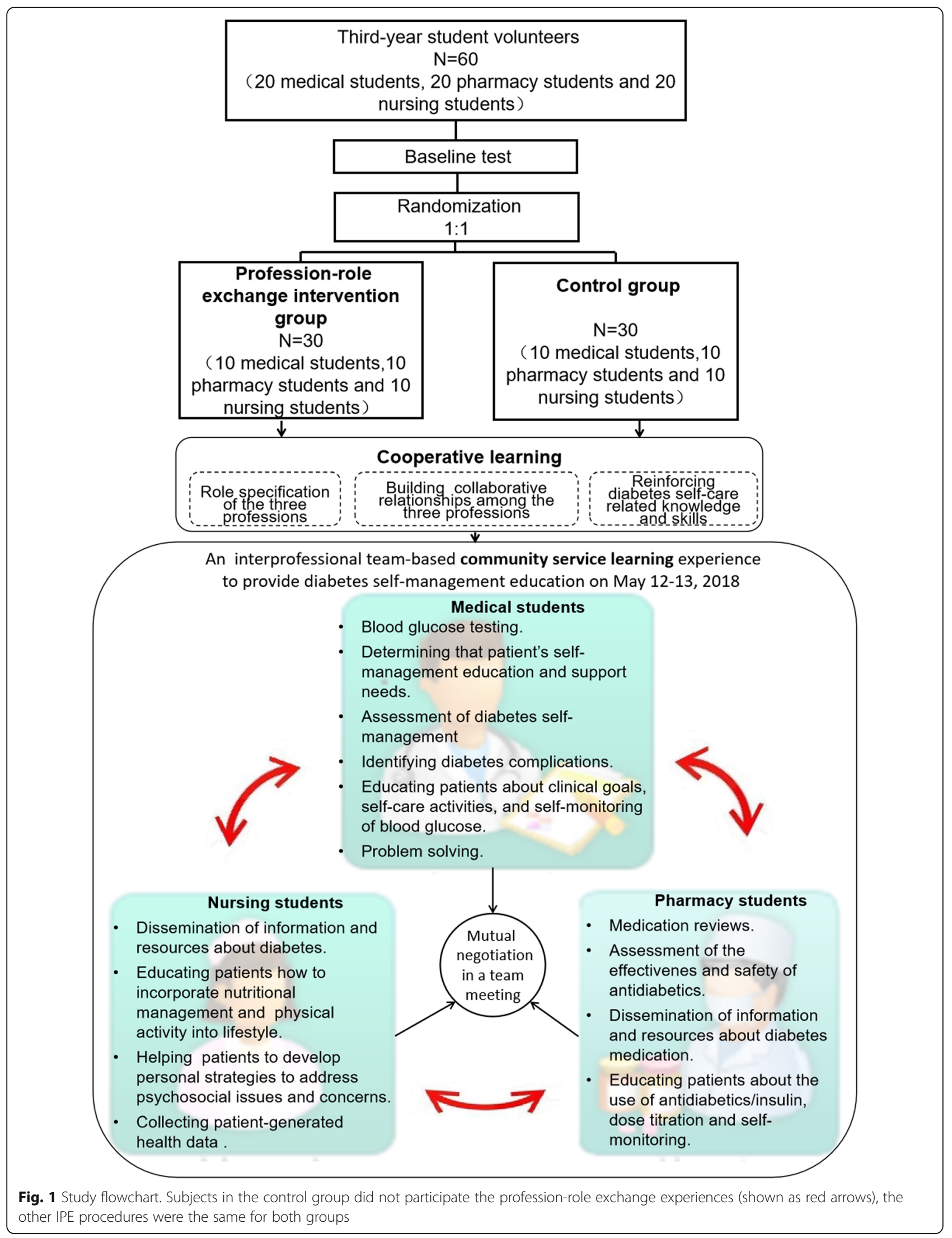


team should act as a student physician; the other pharmacy student should adopt characters or roles of the nursing students in their team, and so on. The rolechoices of students were based on their own will and the negotiation among the team members. As students began the role-exchange experiences, they were allowed to consult with their peers, but could not let other students work instead of themselves.

Subjects in the control group did not participate the profession-role exchange experiences, the other IPE procedures (Step 1 and 2) were the same for both groups. The above IPE experience was governed by a volunteer faculty committee, and under the supervision of three qualified practitioners.

\section{Measures}

\section{Physician-pharmacist collaboration survey instrument}

As common-used validated instrument for measuring interprofessional collaboration between physicians and pharmacists [7, 21], Scale of Attitudes Toward PhysicianPharmacist Collaboration $\left(\mathrm{SATP}^{2} \mathrm{C}\right)$ was applied to measure the perceptions of physician-pharmacist collaboration among the involved medical and pharmacy students. There are 16 Likert-type items on a 4-point scale (4: strongly agree; 3 :agree; 2 : disagree or 1:strongly disagree) in $\mathrm{SATP}^{2} \mathrm{C}$. Higher scores mean more positive attitudes toward physician-pharmacist collaborative relationships.

\section{Physician-nurse collaboration survey instrument}

The medical and nursing students in both intervention and control groups were required to complete the Jefferson Scale of Attitudes Towards Physician-Nurse Collaboration (JSAPNC) [22], which included 15 items on a 4point scale (1:strongly disagree-4:strongly agree). A higher total score indicates a more positive attitude toward physician-nurse collaboration.

\section{Nurse-pharmacist collaboration survey instrument}

The attitudes toward nurse-pharmacist collaboration among the nursing and pharmacy students were analyzed using a previously self-developed 25-item scale [23], the overall score of which ranges from 25 to 100 theoretically. Higher scores reflect more positive attitudes toward nurse-pharmacist collaboration.

\section{"Roles and responsibilities" subscale of Readiness for Interprofessional Learning Scale (RIPLS)}

All the participant students were asked for responses to "Roles and responsibilities" subscale of RIPLS, which was firstly developed by Parsell \& Bligh [24] to assess the readiness of health-care students for multi-professional learning. There are three underlying factors in RIPLS, which were respectively named as "Team-working and collaboration", "Professional-identity" and "Roles and responsibilities" [25]. Among them, "Roles and responsibilities" subscale of RIPLS has been widely used to specially evaluate the overall role clarification during IPE $[18,26]$. This subscale includes 3 items rated on a 5-point scale, ranging from (1: strongly Disagree - 5: strongly agree). Higher total scores indicate greater role clarification.

The bilingual version of the above survey instruments in Chinese and English was applied in this study to ensure the accurate comprehension of respondents.

\section{Data collection}

At the initial meeting before beginning the IPE intervention, students received a letter of information and the printed questionnaires. Only participants completing the questionnaires were included in the subsequent study. Participants received the same questionnaires immediately following the community service-learning experience. All 60 students completed the pre-study questionnaires, but a medical student in the profession-role exchange intervention group and a nursing student in control group did not complete the post-study questionnaires thus were excluded from analyses.

\section{Data analysis}

Data were coded and entered into SPSS22.0. Results were expressed as mean \pm standard deviation (SD). Previous studies have identified underlying factors of $\mathrm{SATP}^{2} \mathrm{C}$ [21], JSAPNC [22], Nurse-pharmacist collaboration survey instrument [23], and RIPLS [24] (Tables 1, 2 and 3, Fig. 2). In order to assess the levels of attitudes toward interprofessional collaboration or role clarification and their distribution among different factors, total scores from survey instruments as well as the scores for each extracted factor were recorded. The Wilcoxon matchedpairs signed rank test was used to compare the differences between the results from pre- and post-study surveys. Repeated-measures ANOVA using pre- and postintervention scores as the within-subject factor and intervention (yes or no) as the between-subject factor was conducted to investigate the differences between the outcomes of the profession-role exchange intervention group and the control group. Differences were considered to be statistically significant when $p$-value $<0.05$.

\section{Results}

Because all the participants were the third-year students, their ages were all around 21. Among 29 control students who completed both pre-study and post-study questionnaires, 9 were males and 20 were females. The professionrole exchange intervention group had the same gender distribution as the control group. Collectively, the gender, age, specialty, or grade distribution of participants was approximately equal between the two groups. 
Table 1 The effect of profession-role exchange intervention on the students' attitudes towards physician-pharmacist collaboration measured with SATP² (Mean \pm SD)

\begin{tabular}{|c|c|c|c|c|c|c|c|c|c|}
\hline \multirow[t]{3}{*}{ Factors } & \multirow[t]{3}{*}{ Score range (Min.-Max.) } & \multicolumn{4}{|c|}{ Medical students } & \multicolumn{4}{|c|}{ Pharmacy students } \\
\hline & & \multicolumn{2}{|c|}{ Control group $(n=10)$} & \multicolumn{2}{|c|}{$\begin{array}{l}\text { Intervention } \\
\text { group }(n=9)\end{array}$} & \multicolumn{2}{|c|}{ Control group $(n=10)$} & \multicolumn{2}{|c|}{$\begin{array}{l}\text { Intervention } \\
\text { group }(n=10)\end{array}$} \\
\hline & & $\begin{array}{l}\text { Pre- } \\
\text { activity }\end{array}$ & $\begin{array}{l}\text { Post- } \\
\text { activity }\end{array}$ & $\begin{array}{l}\text { Pre- } \\
\text { activity }\end{array}$ & $\begin{array}{l}\text { Post- } \\
\text { activity }\end{array}$ & $\begin{array}{l}\text { Pre- } \\
\text { activity }\end{array}$ & Post-activity & $\begin{array}{l}\text { Pre- } \\
\text { activity }\end{array}$ & $\begin{array}{l}\text { Post- } \\
\text { activity }\end{array}$ \\
\hline $\begin{array}{l}\text { Responsibility and } \\
\text { accountability }\end{array}$ & $9-36$ & $27.8 \pm 3.8$ & $31.4 \pm 2.6^{* *}$ & $28.0 \pm 2.9$ & $33.4 \pm 2.2^{* * \#}$ & $29.8 \pm 2.6$ & $32.6 \pm 2.5^{* *}$ & $29.2 \pm 2.7$ & $33.9 \pm 2.3^{* * \#}$ \\
\hline Shared authority & $5-20$ & $14.9 \pm 1.7$ & $18.0 \pm 1.5^{* *}$ & $15.2 \pm 1.7$ & $19.0 \pm 1.0^{* * \#}$ & $16.0 \pm 1.7$ & $18.3 \pm 1.7^{* *}$ & $15.6 \pm 1.4$ & $18.9 \pm 1.3^{* * \#}$ \\
\hline $\begin{array}{l}\text { Interdisciplinary } \\
\text { education }\end{array}$ & $2-8$ & $6.4 \pm 1.1$ & $8.4 \pm 0.8^{* *}$ & $6.7 \pm 1.1$ & $9.1 \pm 0.8^{* *}$ & $6.8 \pm 1.1$ & $8.7 \pm 1.2^{* *}$ & $7.3 \pm 1.4$ & $9.3 \pm 0.8^{* *}$ \\
\hline Total scores & $16-64$ & $49.1 \pm 5.0$ & $57.8 \pm 3.4^{* *}$ & $49.9 \pm 4.3$ & $61.6 \pm 2.88^{* * \#}$ & $52.6 \pm 3.3$ & $59.6 \pm 2.7^{* *}$ & $52.1 \pm 3.0$ & $62.1 \pm 3.7^{* * \#}$ \\
\hline
\end{tabular}

${ }^{*} p<0.05 ;{ }^{* *} p<0.01$. Pre- and post-activity surveys were analysed using the Wilcoxon matched-pairs signed rank test

${ }^{\#} p<0.05$. Repeated-measures ANOVA using pre- and post-intervention scores as the within-subject factor and intervention (yes or no) as the between-subject factor was conducted to investigate the differences between the outcomes of the profession-role exchange intervention group and the control group

\section{Medical and pharmacy students' attitudes toward physician-pharmacist collaboration}

All the medical and pharmacy participants in the IPE activity, except a medical student, completed both the preand post-activity surveys on attitudes toward physicianpharmacist collaboration using $\mathrm{SATP}^{2} \mathrm{C}$. As shown in Table 1, after the IPE activity, significant enhancements in $\mathrm{SATP}^{2} \mathrm{C}$ scores were found in both control and intervention groups $(p<0.01)$. Importantly, when compared with the control group, the addition of profession-role exchange in the intervention group markedly further increased the total $\mathrm{SATP}^{2} \mathrm{C}$ scores $(p<0.05)$. In the control group, the total $\mathrm{SATP}^{2} \mathrm{C}$ scores were increased by 17.7 and $13.3 \%$ for medical and pharmacy students, respectively; in the intervention group, the total scores were respectively increased by 23.4 and $19.2 \%$ for medical and pharmacy participants.

Three underlying constructs, namely "Responsibility and accountability", "Shared authority" and "Interdisciplinary education", had been emerged from the factor analysis of $\mathrm{SATP}^{2} \mathrm{C}[21]$. In line with the changes in the total scores, for the medical and pharmacy students, participating in the profession-role exchange was associated with the increased scores in "Responsibility and accountability" and "Shared authority" subscales on the $\operatorname{SATP}^{2} \mathrm{C}$ ( $p<0.05$, vs. control group).

\section{Medical and nursing students' attitudes toward physician- nurse collaboration}

As shown in Table 2, significant statistical differences $(p<0.01)$ in the total JSAPNC scores were found between pre-activity and post-activity in both control and intervention groups. And the increases of the total score in the medical and nursing students who had experienced profession-role exchange (31.6 and 29.7\%, respectively) was more markedly than those of the control students ( 17.4 and $16.1 \%$, respectively).

Among the four extracted factors of JSAPNC, it was interesting to found that, after the intervention of professionrole exchange, medical and nursing students displayed significantly more positive attitudes toward "Nurse's autonomy" and "Physician's dominance" $(p<0.05)$, which are

Table 2 The effect of profession-role exchange intervention on the students' attitudes towards physician-nurse collaboration measured with JSAPNC (Mean \pm SD)

\begin{tabular}{|c|c|c|c|c|c|c|c|c|c|}
\hline \multirow[t]{3}{*}{ Factors } & \multirow[t]{3}{*}{ Score range (Min.-Max.) } & \multicolumn{4}{|c|}{ Medical students } & \multicolumn{4}{|c|}{ Nursing students } \\
\hline & & \multicolumn{2}{|c|}{ Control group $(n=10)$} & \multicolumn{2}{|c|}{$\begin{array}{l}\text { Intervention group } \\
(n=9)\end{array}$} & \multicolumn{2}{|c|}{ Control group $(n=9)$} & \multicolumn{2}{|c|}{$\begin{array}{l}\text { Intervention group } \\
(n=10)\end{array}$} \\
\hline & & $\begin{array}{l}\text { Pre- } \\
\text { activity }\end{array}$ & $\begin{array}{l}\text { Post- } \\
\text { activity }\end{array}$ & $\begin{array}{l}\text { Pre- } \\
\text { activity }\end{array}$ & $\begin{array}{l}\text { Post- } \\
\text { activity }\end{array}$ & $\begin{array}{l}\text { Pre- } \\
\text { activity }\end{array}$ & $\begin{array}{l}\text { Post- } \\
\text { activity }\end{array}$ & $\begin{array}{l}\text { Pre- } \\
\text { activity }\end{array}$ & $\begin{array}{l}\text { Post- } \\
\text { activity }\end{array}$ \\
\hline $\begin{array}{l}\text { Shared education } \\
\text { and team work }\end{array}$ & $7-28$ & $21.2 \pm 1.5$ & $24.7 \pm 1.7^{* *}$ & $20.8 \pm 1.9$ & $24.9 \pm 1.9^{* *}$ & $21.1 \pm 2.0$ & $24.6 \pm 1.7^{* *}$ & $20.8 \pm 1.6$ & $25.2 \pm 2.3^{* *}$ \\
\hline Caring vs. curing & $3-12$ & $8.9 \pm 1.1$ & $10.6 \pm 1.1^{* *}$ & $8.9 \pm 0.9$ & $11.4 \pm 1.3^{* *}$ & $9.0 \pm 1.4$ & $11.1 \pm 1.2^{* *}$ & $8.8 \pm 1.5$ & $10.7 \pm 1.1^{* *}$ \\
\hline Nurse's autonomy & $3-12$ & $6.0 \pm 2.4$ & $7.2 \pm 3.0$ & $5.7 \pm 1.9$ & $9.3 \pm 2.4^{* * \#}$ & $6.4 \pm 1.7$ & $8.0 \pm 1.7^{*}$ & $6.1 \pm 2.0$ & $9.3 \pm 2.3^{* * \#}$ \\
\hline Physician's dominance & $2-8$ & $3.6 \pm 1.5$ & $4.1 \pm 2.0$ & $3.9 \pm 1.5$ & $6.0 \pm 1.9^{* * \#}$ & $4.6 \pm 2.1$ & $4.0 \pm 1.1$ & $4.7 \pm 2.3$ & $7.2 \pm 1.3^{* * \#}$ \\
\hline Total scores & $15-60$ & $39.7 \pm 4.0$ & $46.6 \pm 4.8^{* *}$ & $39.3 \pm 3.1$ & $51.7 \pm 4.4^{* \# \#}$ & $41.1 \pm 2.2$ & $47.7 \pm 1.9^{* *}$ & $40.4 \pm 3.0$ & $52.4 \pm 3.4^{* * \#}$ \\
\hline
\end{tabular}


Table 3 The effect of profession-role exchange intervention on the students' attitudes towards nurse-pharmacist collaboration measured with the nurse-pharmacist collaboration survey instrument (Mean $\pm \mathrm{SD}$ )

\begin{tabular}{|c|c|c|c|c|c|c|c|c|c|}
\hline \multirow[t]{3}{*}{ Factors } & \multirow[t]{3}{*}{ Score range (Min.-Max.) } & \multicolumn{4}{|c|}{ Pharmacy students } & \multicolumn{4}{|c|}{ Nursing students } \\
\hline & & \multicolumn{2}{|c|}{ Control group $(n=10)$} & \multicolumn{2}{|c|}{$\begin{array}{l}\text { Intervention group }(n= \\
10)\end{array}$} & \multicolumn{2}{|c|}{ Control group $(n=9)$} & \multicolumn{2}{|c|}{$\begin{array}{l}\text { Intervention group } \\
(n=10)\end{array}$} \\
\hline & & $\begin{array}{l}\text { Pre- } \\
\text { activity }\end{array}$ & $\begin{array}{l}\text { Post- } \\
\text { activity }\end{array}$ & $\begin{array}{l}\text { Pre- } \\
\text { activity }\end{array}$ & $\begin{array}{l}\text { Post- } \\
\text { activity }\end{array}$ & Pre-activity & $\begin{array}{l}\text { Post- } \\
\text { activity }\end{array}$ & $\begin{array}{l}\text { Pre- } \\
\text { activity }\end{array}$ & $\begin{array}{l}\text { Post- } \\
\text { activity }\end{array}$ \\
\hline $\begin{array}{l}\text { Interprofessional } \\
\text { team- based practice }\end{array}$ & $11-44$ & $30.6 \pm 3.8$ & $35.4 \pm 5.1^{* *}$ & $30.7 \pm 4.9$ & $37.3 \pm 5.0^{* *}$ & $29.4 \pm 5.0$ & $35.2 \pm 4.8^{* *}$ & $29.5 \pm 5.1$ & $37.5 \pm 2.8^{* *}$ \\
\hline $\begin{array}{l}\text { Roles/responsibilities } \\
\text { for collaborative } \\
\text { practice }\end{array}$ & $7-28$ & $17.8 \pm 6.1$ & $21.2 \pm 6.3$ & $17.3 \pm 6.4$ & $25.0 \pm 1.5^{* * \#}$ & $13.4 \pm 5.7$ & $18.4 \pm 6.0^{*}$ & $16.0 \pm 6.2$ & $24.7 \pm 2.5^{* * \#}$ \\
\hline $\begin{array}{l}\text { Relationship } \\
\text { between nurses and } \\
\text { pharmacists }\end{array}$ & $4-16$ & $10.4 \pm 3.2$ & $12.7 \pm 3.0^{*}$ & $11.2 \pm 2.0$ & $13.9 \pm 1.4^{* *}$ & $8.9 \pm 2.7$ & $12.2 \pm 1.6^{* *}$ & $9.6 \pm 2.2$ & $12.8 \pm 1.7^{* *}$ \\
\hline $\begin{array}{l}\text { Nurses' experience } \\
\text { of pharmacist's role } \\
\text { in drug treatment }\end{array}$ & $3-12$ & $10.4 \pm 1.3$ & $11.7 \pm 0.7^{* *}$ & $10.4 \pm 1.6$ & $11.6 \pm 0.7^{*}$ & $9.4 \pm 1.1$ & $10.3 \pm 1.5$ & $8.5 \pm 2.2$ & $11.0 \pm 1.3^{* * \#}$ \\
\hline Total scores & $25-100$ & $69.2 \pm 9.8$ & $81.0 \pm 12.6^{*}$ & $69.6 \pm 7.5$ & $87.8 \pm 7.1^{* * \#}$ & $61.2 \pm 11.2$ & $76.2 \pm 9.9^{* *}$ & $63.6 \pm 6.3$ & $86.0 \pm 3.6^{* * \#}$ \\
\hline
\end{tabular}

${ }^{*} p<0.05 ;{ }^{* *} p<0.01$. Pre- and post-activity surveys were analysed using the Wilcoxon matched-pairs signed rank test

$\# p<0.05$. Repeated-measures ANOVA using pre- and post-intervention scores as the within-subject factor and intervention (yes or no) as the between-subject factor was conducted to investigate the differences between the outcomes of the profession-role exchange intervention group and the control group

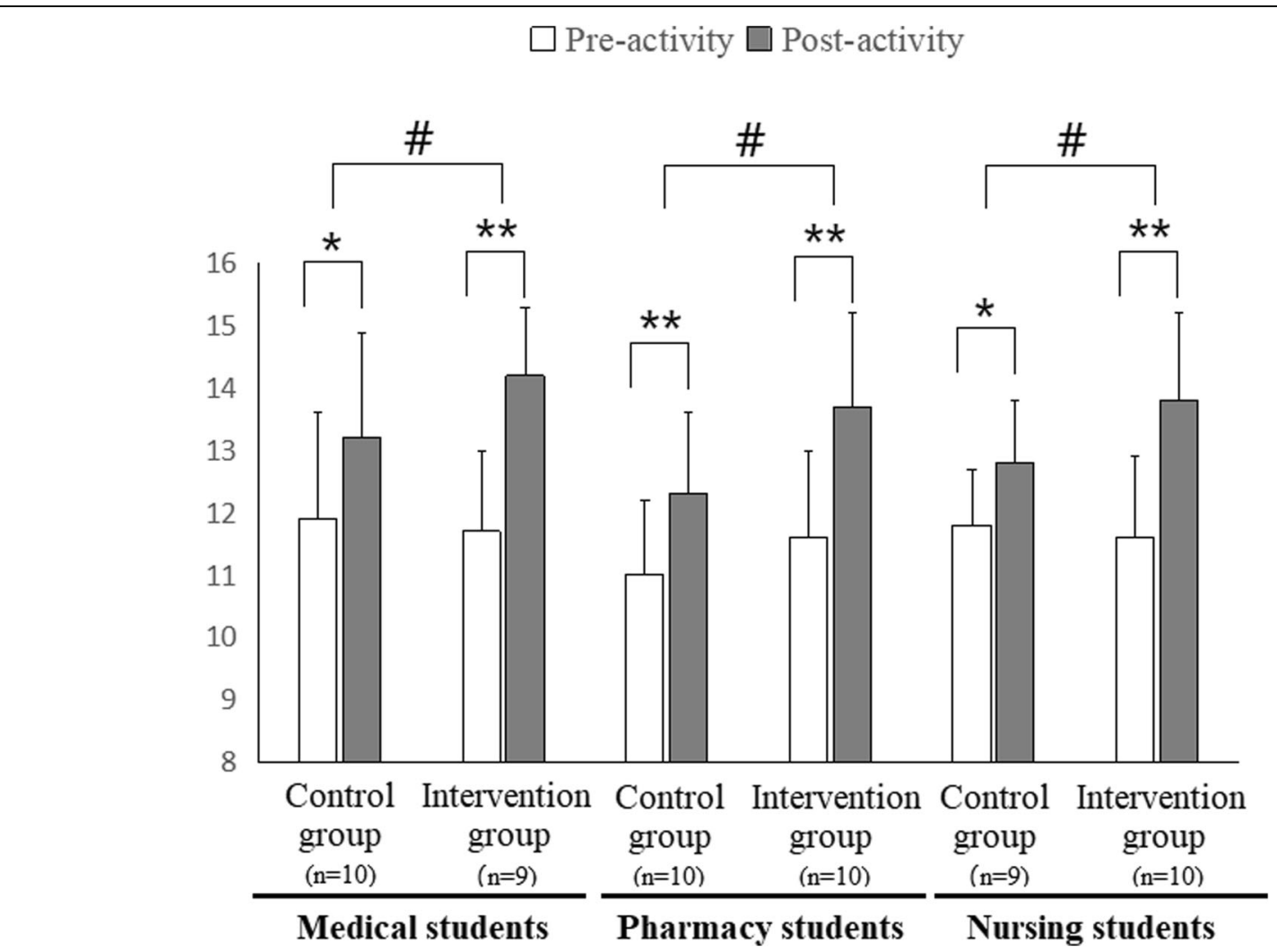

Fig. 2 The effect of profession-role exchange intervention on the students' scores in "Roles and responsibilities" subscale of RIPLS (Mean \pm SD). ${ }^{*} p<0.05 ;{ }^{*} p<0.01$. Pre- and post-activity surveys were analysed using the Wilcoxon matched-pairs signed rank test. \# $p<0.05$. Repeatedmeasures ANOVA using pre- and post-intervention scores as the within-subject factor and intervention (yes or no) as the between-subject factor was conducted to investigate the differences between the outcomes of the profession-role exchange intervention group and the control group 
factors reflecting students' perceptions of professional role. A higher factor score on the "Nurses' autonomy" dimension suggested a more positive view of nurses' importance in decisions about patient care [27]. As for two reversely-scored items identified as "Physician's dominance" questions, more students showed a rejection of physicians' totally dominant role in patient care after profession-role exchange intervention $(p<0.05)$. These data suggested that the professionrole exchange experiences reversed the common rolestereotype of nurses as "collaborators" and physicians as "team leaders".

\section{Nursing and pharmacy students' attitudes toward nurse- pharmacist collaboration}

As shown in Table 3, despite the fact that the control IPE activity increased the total attitude scores toward nurse-pharmacist collaboration among nursing and pharmacy students by 17.1 and $24.5 \%$, respectively $(p<$ $0.05 ; p<0.01$, vs. pre-activity), the integration of profession-role exchange experience into the IPE activity achieved further improvement $(p<0.05$, vs. control group). Importantly, the nursing and pharmacy students' attitudes toward "Roles/responsibilities for collaborative practice" were significantly enhanced by the professionrole exchange experiences $(44.5 \%$ in pharmacy students and $54.4 \%$ in nursing students of the intervention group vs. $19.1 \%$ in pharmacy students and $37.3 \%$ in nursing students of control group). And the nursing students' scores in the "Nurses' experience of pharmacist's role in drug treatment" sub-scale were obviously decreased by $29.4 \%$ after the profession-role exchange intervention, when compared with those of control nursing students $(p<0.05)$.

\section{Students' scores in "Roles and responsibilities" subscale of RIPLS}

As shown in Fig. 2, in the control group, the medical, pharmacy and nursing students' scores in "Roles and responsibilities" subscale of RIPLS were respectively enhanced by $10.9,11.8$ and $8.5 \%$ after the control IPE activity $(p<0.05 ; p<0.01)$. In the profession-role exchange intervention group, the scores of medical, pharmacy and nursing students were enhanced by 21.4, 18.1 and $19.0 \%$, respectively $(p<0.05 ; p<0.01)$. The between-group comparison showed that participating in the profession-role exchange further increased the scores in the role understanding subscale of RIPLS among students from any of the three health-care professions $(p<0.05)$.

\section{Discussion}

Role-play, as an integral part of simulation-based education method in experiential learning, has been demonstrated to allow for the multi-level brain processing of experiences, thus be effective in constructing the cognitive and emotional learning of health-care students $[28,29]$. However, previous educational studies were usually associated with students in single roles during simulation rather than assuming multiple roles [28], which might hinder the students from a comprehensive learning experience in the simulation modality. Therefore, several authors advocated the use of a special kind of role playing named as "role reversal" [30],"dual roleplay" [31], or "peer role play" [32] as a teaching strategy whereby health-care students assume multiple roles in role-play simulation. No matter what name it was given, this kind of role-play simulation intervention highlighted the importance of perspective taking in the experiential learning. Nevertheless, all these previous studies [30-32] focused on the switching of roles to experience between health-care professional and patient perspectives. In the present study, we firstly used the role exchange between different professions in the interprofessional student team.

Profession-role exchange in this study offered the health-care students some insight into the experience of being the other professional members in interprofessional clinical team. Due to the multiple roles (including: the role that the student played, his/her own profession role, the role of other cooperative team members that other students played) in the IPE programme, students could immersively experience the interprofessional team working, and develop interprofessional knowledge and skills within the same simulation scenario. Here, the profession-role exchange was combined into an integrated learning method of cooperative learning and community service-learning, which we previously presented [7], in order to further improve the effectiveness of the designed extracurricular IPE activity. This study used the previously designed IPE learning method of cooperative learning and community service-learning as the control, and studied the effect of the addition of profession-role exchange as the intervention on the students' attitudes towards interprofessional collaboration and their role understanding. The results showed a significant facilitating effect on the respondents' orientation toward interprofessional team work and the role perceptions of team members in both the intervention group and the control group. Importantly, this effect is more pronounced after experiencing the addition of profession-role exchange than after experiencing with the control IPE activity without profession-role exchange component. In the control group, cooperative learning in which students were required to work together to learn and discuss in small-group learning situations was integrated prior to an interprofessional team-based community service. Cooperative learning experience helped students to prepare the knowledge and skills required in the subsequent community service, clarify their own 
professional roles, develop the team structure and a better understanding of the other professions' roles, thus could encourage shared thinking among team members and lay the foundation for interprofessional community service learning [7]. In the intervention group, the addition of interprofessional role-exchange intervention offered a perspective taking experience that allowed students to understand other professionals' roles in the practical team-based community health-care work, to reflect on their own past professional skills, as well as to understand the importance of interprofessional communication and collaboration. Moreover, this professionrole exchange experience provided opportunities for students to actually apply the knowledge and skills which they had prepared during the cooperative learning activities.

In this study, three survey instruments for attitudes toward interprofessional clinical collaboration, including SATP $^{2} \mathrm{C}$ [21], JSAPNC [22] and a self-developed 25-item scale [23], were used to measure the students' attitudes toward physician- pharmacist, physician-nurse and nursepharmacist collaborations, respectively. The profession-role exchange significantly enhance the scores in some extracted factors, especially "Responsibility and accountability" and "Shared authority" in SATP $^{2}$ C; "Nurse's autonomy" and "Physician's dominance" in JSAPNC; "Roles/responsibilities for collaborative practice" and "Nurses' experience of pharmacist's role in drug treatment" in the nurse-pharmacist collaboration survey instrument, which reflected the respondents' professional role clarification. Moreover, the results from "Roles and responsibilities" sub-scale of RIPLS also indicated that the students' understanding of roles of their own and other interrelated professions was further fostered after participating in the profession-role exchange experiences. These data showed that the experiences of students in role simulation as their cooperative team members in the teamwork situation were effective in strengthening the role identity and the communication among professions in the clinical setting. In their role as collaborators, health-care students have an opportunity to observe their own role in interprofessional collaboration from a new perspective, decide what elements to adopt in their own future clinical practice, and integrate their past professional knowledge and experiences to a novel situation for a creative solution.

Therefore, the combine of profession-role exchange with the cooperative learning-based community service IPE activity could further help students to develop the role perceptions of other health-care professionals, as well as hone their self-awareness, enhance interprofessional collaborative skill acquisition in a safe environment, thus prepare students for future real interprofessional contacts in a collaborative environment, allow for optimal contributions from all team members in providing holistic patient care. The integration of profession-role exchange component in an interprofessional student team-based community health service-learning experience could be used as a comprehensive extracurricular IPE tool for improving the role awareness of health-care students. This study provided a referential model for the professional role assignment during the further simulated IPE programs.

This study contained some limitations. $\operatorname{SATP}^{2} \mathrm{C}$, JSAPNC and a previously self-developed 25 -item scale were respectively chosen to detect students' attitudes toward physician-pharmacist, physician-nurse and nursepharmacist collaboration. The "Roles and responsibilities" sub-scale of RIPLS was used to measure the overall role clarification. Although previous studies [21-24] have provided support for the validity and reliability of these measurement tools, the psychometric integrity of the Chinese and English bilingual versions of these instruments used in this study is still limited. Therefore, the psychometric properties of these chosen instruments as well as the internal consistency among items within each questionnaire measure should be further critically appraised. Because attitudes are only a proxy for behavior, it might be more ideal to demonstrate that this program can improve the communications and collaborative working in the workplace. However, there is still no quantitative method to measure the interprofessional collaboration behavior. Moreover, a total of 60 students were recruited in this study. In the studied university, there are about 300 medical students, 60 pharmacy students and 60 nursing students at each grade level. Therefore, the overall proportion of participants is less than $15 \%$. And because the study participants are volunteers, it is unclear whether they represent all students. Furthermore, subjects were not randomly assigned to intervention or control group, so they were fully aware of the group they were in, which possibly caused socially-desired responses. In addition, the intervention of profession-role exchange was conducted only once. The small sample size and single-institution nature may limit the generalizability of the results. Further research and replication of this study with a larger sample of students from multiple institutions are needed to strengthen our findings.

\section{Conclusions}

Our study concluded that a profession-role exchange component introduced in an interprofessional student team-based community health service-learning experience allowed the health-care students to experience the perspectives of their partners in the clinical team work under the community-based learning model. The profession-role exchange intervention resulted in the enhancement of students' role awareness in interprofessional collaboration, thus could be used as an effective IPE tool. 


\section{Abbreviations}

IPE: Interprofessional education; JSAPNC: Jefferson scale of attitudes towards physician-nurse collaboration; RIPLS: Readiness for interprofessional learning scale; SATP ${ }^{2}$ C: Scale of attitudes toward physician-pharmacist collaboration; SD: Standard deviation

\section{Acknowledgements}

We thank all persons who participated in our study.

\section{Authors' contributions}

JW and $\mathrm{XH}$ contributed to the design of the research, JW, JG, YW, DY, JL, YZ and $\mathrm{XH}$ carried out the intervention and data acquisition. JW, JG and $\mathrm{XH}$ analyzed, interpreted the data. JW and XH prepared the article. All authors read and approved the final manuscript.

\section{Funding}

This work was funded by the medical education research project from Medical education branch of the Chinese medical association and medical education professional committee of the Chinese association of higher education (2018B-N02084), the educational science planning project in Hubei province (2019GB019), and the Provincial Teaching Research Project in Hubei (2014230).

\section{Availability of data and materials}

The datasets used and/or analysed during the current study are available from the corresponding author on reasonable request.

\section{Ethics approval and consent to participate}

Approval was obtained from the Ethics Committee of Medicine College, Wuhan University of Science and Technology (2018039). Written informed consents were obtained from the study participants.

\section{Consent for publication}

Not applicable.

\section{Competing interests}

The authors declare that they have no competing interests.

Received: 24 February 2020 Accepted: 25 June 2020

Published online: 02 July 2020

\section{References}

1. Wan S, Teichman PG, Latif D, Boyd J, Gupta R. Healthcare provider perceptions of the role of interprofessional care in access to and outcomes of primary care in an underserved area. J Interprof Care. 2018;32(2):220-3.

2. Bochatay N, Muller-Juge V, Scherer F, et al. Are role perceptions of residents and nurses translated into action? BMC Med Educ. 2017;17(1):138.

3. Benson H, Lucas C, Benrimoj SI, Williams KA. The development of a role description and competency map for pharmacists in an interprofessional care setting. Int J Clin Pharm. 2019:41(2):391-407.

4. Supper I, Catala O, Lustman M, Chemla C, Bourgueil Y, Letrilliart L. Interprofessional collaboration in primary health care: a review of facilitators and barriers perceived by involved actors. J Public Health (Oxf). 2015;37(4): 716-27.

5. Bittner CA. The importance of role clarity for development of Interprofessional teams. J Contin Educ Nurs. 2018;49(8):345-7.

6. Saxe JM, Balano K, Wamsley M, Nakajima M, Brock T. Promoting role clarity for health professional students participating in an Interprofessional behavior change counseling workshop. J Allied Health. 2017;46(2):e35-7.

7. Wang J, Hu X, Liu J, Li L. Pharmacy students' attitudes towards physicianpharmacist collaboration: intervention effect of integrating cooperative learning into an interprofessional team-based community service. J Interprof Care. 2016;30(5):591-8

8. Macdonald MB, Bally JM, Ferguson LM, Lee Murray B, Fowler-Kerry SE, Anonson JM. Knowledge of the professional role of others: a key interprofessional competency. Nurse Educ Pract. 2010;10(4):238-42.

9. Morin C, Desrosiers J, Gaboury I. Enablers and barriers to the development of interprofessional collaboration between physicians and osteopaths: a mixed methods study. J Interprof Care. 2018;32(4):463-72.

10. Homeyer S, Hoffmann W, Hingst P, Oppermann RF, Dreier-Wolfgramm A. Effects of interprofessional education for medical and nursing students: enablers, barriers and expectations for optimizing future interprofessional collaboration - a qualitative study. BMC Nurs. 2018;17:13.

11. von der Lancken S, Gunn E. Improving role identity by shadowing interprofessional team members in a clinical setting: an innovative clinical education course. J Interprof Care. 2019;33(5):464-71.

12. Ryan $M$, Vanderbilt $A A$, Mayer SD, Gregory A. Interprofessional education as a method to address health needs in a Hispanic community setting: a pilot study. J Interprof Care. 2015;29(5):515-7.

13. Glicken A. Innovations in faculty development: interprofessional oral health workshops combine active learning and community engagement. J Physician Assist Educ. 2014;25(3):31-5.

14. Sullivan K, Charrette A, Massey C, et al. Interprofessional education with a community fall prevention event. J Interprof Care. 2015;29(4):374-6.

15. Moton R, Baus C, Brandt C, et al. Stop the bleed: an Interprofessional community service learning project assessing the efficacy of pharmacist-led hemorrhage control education for laypersons. Disaster Med Public Health Prep. 2020;31:1-6. https://doi.org/10.1017/dmp.2020.8.

16. Hall P, Weaver L. Interdisciplinary education and teamwork: a long and winding road. Med Educ. 2001;35(9):867-75.

17. Cauley K, Canfield A, Clasen C, et al. Service learning: integrating student learning and community service. Educ Health (Abingdon). 2001;14(2):17381.

18. Hudson CC, Gauvin S, Tabanfar R, Poffenroth AM, Lee JS, O'Riordan AL. Promotion of role clarification in the health care team challenge. J Interprof Care. 2017;31(3):401-3.

19. Xue-Juan W, Hao W, Cai-Ying G, et al. Impact of an intelligent chronic disease management system on patients with type 2 diabetes mellitus in a Beijing community. BMC Health Serv Res. 2018;18(1):821.

20. Beck J, Greenwood DA, Blanton L, et al. 2017 National Standards for diabetes self-management education and support. Diabetes Educ. 2020; 46(1):46-61.

21. Hojat M, Spandorfer J, Isenberg GA, Vergare MJ, Fassihi R, Gonnella JS Psychometrics of the scale of attitudes toward physician-pharmacist collaboration: a study with medical students. Med Teach. 2012;34(12):e8337.

22. Hojat M, Fields SK, Veloski JJ, Griffiths M, Cohen MJ, Plumb JD. Psychometric properties of an attitude scale measuring physician-nurse collaboration. Eval Health Prof. 1999;22(2):208-20.

23. Wang SP, Wang J, Huang QH, Zhang YH, Liu J. Pharmacy and nursing students' attitudes toward nurse-pharmacist collaboration at a Chinese university. BMC Med Educ. 2018;18(1):179.

24. Parsell G, Bligh J. The development of a questionnaire to assess the readiness of health care students for interprofessional learning (RIPLS). Med Educ. 1999:33(2):95-100.

25. McFadyen AK, Webster V, Strachan K, Figgins E, Brown H, McKechnie J. The readiness for Interprofessional learning scale: a possible more stable sub-scale model for the original version of RIPLS. J Interprof Care. 2005;19(6):595-603.

26. Stull $\mathrm{CL}$, Blue $\mathrm{CM}$. Examining the influence of professional identity formation on the attitudes of students towards interprofessional collaboration. J Interprof Care. 2016;30(1):90-6.

27. Hojat M, Gonnella JS, Nasca TJ, et al. Comparisons of American, Israeli, Italian and Mexican physicians and nurses on the total and factor scores of the Jefferson scale of attitudes toward physician-nurse collaborative relationships. Int J Nurs Stud. 2003;40(4):427-35.

28. McNamara N. Preparing students for clinical placements: the student's perspective. Nurse Educ Pract. 2015;15(3):196-202

29. Young J. Using a role-play simulation game to promote systems thinking. J Contin Educ Nurs. 2018;49(1):10-1.

30. Mathews IL, Parkhill AL, Schlehofer DA, Starr MJ, Barnett S. Role-reversal exercise with deaf strong hospital to teach communication competency and cultural awareness. Am J Pharm Educ. 2011;75(3):53.

31. Lim EC, Oh VM, Seet RC. Overcoming preconceptions and perceived barriers to medical communication using a 'dual role-play' training course. Intern Med J. 2008;38(9):708-13.

32. Bosse HM, Schultz JH, Nickel M, et al. The effect of using standardized patients or peer role play on ratings of undergraduate communication training: a randomized controlled trial. Patient Educ Couns. 2012;87(3):300-6.

\section{Publisher's Note}

Springer Nature remains neutral with regard to jurisdictional claims in published maps and institutional affiliations. 